\title{
WHERE IS THE PERSON IN PERSONALITY RESEARCH? ${ }^{1}$
}

\author{
RAE CARLSON 2 \\ Educational Testing Service, Princeton, New Jersey
}

\begin{abstract}
Constraints upon inquiry in personality imposed by current research methods were cxamined by $(a)$ a survey of empirical work published in two major personality joumals and $(b)$ a consideration of methodological and ethical issues raised in recent research criticism. Review of samples, research procedures, and social-psychological context in 226 empirical studies revealed that current methodological practices are incapable of approaching questions of real importance in personality and involve serious problems beyond those noted in recent research criticism. Recent proposals for methodological reforms of fer only partial solutions and require further attention to the personal involvement and responsibility of investigators. This paper proposes a conceptual schema for ordering personality research strategies, a distinction between "contractual" and "collaborative" models of subject-experimenter relationships, and suggestions for increasing the relevance and responsibility of personality research.
\end{abstract}

The greatly increased volume of empirical work on personality in recent years, and the appearance of several new textbooks on personality research and theory (e.g., Maddi, 1968; Mehrabian, 1968; Mischel, 1968; Schontz, 1965), may be read as indications of flourishing inquiry in personality. Yet there is a growing concern (Adelson, 1969; Sanford, 1965 ) that personology is, in fact, languishing; that in adopting the research values and strategies of "process" psychology, contemporary investigators have relegated the psychology of "person" to a peripheral world of the psychotherapist, the behavior modifier, and the encounter group. Moreover, the increasing concern with general issues emerging in contemporary research on research (Argyris, 1968; Kelman, 1967; Orne, 1962; Rosenthal, 1966; Schultz, 1969; Stricker, 1967) has a particularly keen significance for the field of personality study. A reexamination of the status of personality research may help to clefine these issues.

There is a clear consensus among contemporary personologists concerning the goals, methods, and values informing personality research. While governed by the scientific

\footnotetext{
I Preparation of this paper was supported by a National Institute of Mental Health Special Fellowship administered by Educational Testing Service, Princeton, N. J.

a Requests for reprints should be sent to Rac Carlson, National Institute of Mental Health, Room 10-A-01, 5454 Wisconsin Avenue, Chevy Chase, Maryland 20015.
}

principles and ethical concerns common to all psychology, personality has a unique, central role in the field. As Baughman and Welsh (1962) observed:

Personality bridges the two basic branches of psychology-experimental psychology, which tend toward the biological sciences, and social psychology which is closely allied to the social studies . . . the concepts of personality study can tie together the views of these two arcas and minimize the danger of dehumanization... [through clear locus upon] our unit of study, individual man [pp. 16-17].

The program of personality research has been clearly restated by Maddi (1968):

The personologist is interested in universals ... in the commonalities among people las woll as]... in the attempt to identify and classify differences among people... The personologist is rather unustal in not restricting himself to behavior easily traceable to social and biological pressures of the moment... Of all the social and hiological scientists, then, the personologist believes most deeply in the complexity and individuality of life... his emphasis [is] upon characteristics... that show continuity in time... that seem to have psychological imporiance... that have some ready relationship to the major goals and directions of the person's life... The personologist is interested in all rather than only some of the psychological behavior of the person... Finally ... personologists ... are primarily inlerercsted in the adult human being .... the lruit of development-a congealed personality that excrts a pervasive influence on present and luture behavior... 「pp. 7-9; original italics $]$.

Toward achieving these goals, the personologist employs a wide range of methods: "the 
TABLE 1

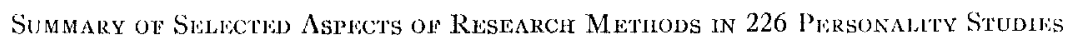

\begin{tabular}{|c|c|c|c|c|c|}
\hline \multicolumn{3}{|c|}{ Sulject samples } & \multicolumn{3}{|c|}{ Research strategy and procedures } \\
\hline Sex composition & $N$ & $\%$ & General strategy & $N$ & $\%$ \\
\hline Males only & 71 & 31 & Experimental & 177 & 78 \\
\hline Iicmales only & 33 & 15 & $\begin{array}{l}\text { liield } \\
\text { lield }\end{array}$ & 47 & 20 \\
\hline Both (specified) & 77 & 34 & Combined & 2 & \\
\hline Both (unspecified) & 22 & 10 & $\ldots \ldots \ldots-\ldots$ & $\ldots$ & - \\
\hline Indeterminate & 23 & 10 & Time span of incluiry & $N$ & $\%$ \\
\hline$\cdots \quad \cdots$ & & $-\ldots$ & 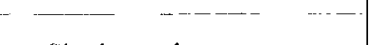 & s. & \\
\hline Age-role composition & N & $\%$ & Single session ${ }^{\sharp}$ & 177 & 78 \\
\hline Jreschool & & $\ldots$ & Less than 1 month & $\begin{array}{l}34 \\
15\end{array}$ & $\begin{array}{r}15 \\
7\end{array}$ \\
\hline lilementary & $\begin{array}{r}2 \\
16\end{array}$ & 7 & Over 1 month & 10 & 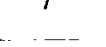 \\
\hline Secondary & 15 & 7 & Cognitive clarity & $N$ & $\%$ \\
\hline College-psychology & 110 & 44 & $\cdots$ & & \\
\hline College & 50 & 22 & Deception & 129 & 57 \\
\hline Adult-general & 3 & $-\dot{6}$ & Debriefing specified & 42 & $(32)^{\mathrm{b}}$ \\
\hline Adult - special & 13 & 6 & Interpretive leedback & 1 & - \\
\hline Multiple & 16 & 8 & $\ldots$ & $-\ldots . .$. & $-\cdots \cdots$ \\
\hline
\end{tabular}

cross-cultural, the developmental, the clinical, the experimental, and the quantitative [Murphy, 1968, p. 19]."

The breadth and depth of the current research stemming from this tradition may be best demonstrated by a review of the current personality literature. Whom are we study ing? How much are we prepared to learn about an individual? In what settings and relationships? Answers to such questions, implicit in the research methods of the field, operate to structure and to limit the possibilities of new knowledge. Assessment of a broad sample of current published research on personality may provide an inclication of whether unexamined assumptions of investiga tors may be restricting, rather than advancing, knowledge about the organization of psychological processes within the person.

The present report, based upon such an assessment of current research, was guided by three purposes: an examination of constraints imposed by research methods, consideration of methodological and ethical issues posed in recent research criticism, and presentation of some alternative ways of solving the problems encountered.

\section{A Surviy of Curkent P'ersonality RESEARCH}

Articles appearing in the 1968 volumes of two major journals publishing substantive research on personality (Journal of Personality and Journal of Personality and Social Psychology) constituted the sample of the review. Since the concern was with the scope and structure of inquiry, rather than its content, subject matter was disregarded, and the focus placed on selected aspects of research method: composition of subject samples, general rcsearch strategy, and social-psychological aspects of the research. Major findings, based upon tabulations for 226 substantive articles (excluding a few editorials, methodological and animal studies, and monograph supplements) are summarized in Table 1.

\section{Whom Are We Studying?}

An overwhelming reliance upon undergraduate students as subjects is clear: $71 \%$ of all studies used college students, with the vast (but indeterminate) majority of these representing introductory psychology students meeting course requirements for research participation. School children, equally "captive" subjects, were a relatively minor second 
choice. The expansion of inquiry to include a broader sample of adults in a variety of community settings (e.g., pregnant mothers, African tribesmen, racetrack patrons) is a heartening development. However, with a few exceptions, community adults were studied in such a limited and trivial fashion as to contribute very little to knowledge of personality.

Males and females were represented in approximately a 2 to 1 ratio, a finding which seems to suggest some correction of the serious imbalance in sex composition of samples noted in a review of the literature nearly a decade ago (Carlson \& Carlson, 1960). However, upon closer examination, this "improvement" appears a remarkably fragile basis for the extension of knowledge. For the sexes are typically studied in segregation: approximately half of the studies used subjects of only one sex, and many of the remaining studies used single-sex groups for separate parts of an investigation. Moreover, one-fifth of the studies either failed to indicate proportions of males and females in the sample or to indicate whether sex varied at all.

Investigators' remarkable lack of interest in an intuitively (and empirically) important aspect of personality appeared in several ways. Among the studies that could have tested for sex differences, less than half reported such tests. Yet in 51 studies where sex differences were examined, significant effects of sex were found in $74 \%$ of the studies. Meanwhile, an implicit awareness of sex differences may be seen in a nascent trend toward using males-only in studying achievement, bargaining, etc., and to use females-only in studying altruism, cooperation, and the like. A most illuminating instance of how sex differences are treated in current research is to be found in a study by Wilson and Insko (1968). In an investigation which combines most of the current preoccupations of the field (e.g., prisoner's dilemma, stooges, evaluative ratings of others, and a "theoretical" controversy), clear-cut findings supporting the major hypothesis were reported on the basis of tables (see Table 2) in which even clearer sex differences failed to capture the attention of the investigators or of journal reviewers.

Given the compelling evidence of the pervasiveness and importance of sex differences in personality, both from present "internal" data and a wealth of "external" evidence (Maccoby, 1966), current research methods seem designed to avoid, rather than to confront, a central problem of personality organization.

\section{How Do We Study Persons?}

Experimental methods predominated in current research, with over half of the published studies employing manipulative procedures. Correlational studies (broadly defined) accounted for most of the remaining work, although a small, but promising upsurge of observational studies in naturalistic settings should be noted. The sole study in which experimental and field methods were combined, and a basic finding established with two appropriate samples, was contributed by a team of sociologists (O'Toole \& Dubin, 1968).

TABLE 2

MEAN STOOgE IMPRESSION

\begin{tabular}{|c|c|c|c|c|c|c|c|c|}
\hline & \multicolumn{4}{|c|}{ No interval belween sessions } & \multicolumn{4}{|c|}{ One wk, belween sessions } \\
\hline & \multicolumn{2}{|c|}{ No measurement delay } & \multicolumn{2}{|c|}{ Measurement delay } & \multicolumn{2}{|c|}{ No measurement delay } & \multicolumn{2}{|c|}{ Measurement delay } \\
\hline & Mate & Ifemale & Male & Female & Malc & Female & Male & liemale \\
\hline Competitive-Cooperative & 34.80 & 34.60 & 35.40 & 35.80 & 34.00 & 37.40 & 37.00 & 37.00 \\
\hline Cooperative-Competitive & 28.60 & 34.00 & 28.40 & 33.60 & 27.00 & 35.40 & 30.40 & 32.00 \\
\hline Difference & 6.20 & .60 & 7.00 & 2.20 & 7.00 & 2.00 & 6.60 & 5.00 \\
\hline Direction & Recency & Recency & Recency & Recency & Recency & Recency & Recency & Recency \\
\hline
\end{tabular}

Note-The recency effect is significant at the .01 level, $F=8.56, d f=1 / 64$; all other effects are nonsignificant.

Repriuted fom an article by Warner Wilson and Chester Insko published in the May 1968 Journal of Personality and Socia psychology. Copyrighted by the American Psychological Association, Inc., 1968. 
IIow Much Are We Prepared to Learn About a l'erson?

Lixtremes of a "comprehensiveness" dimension are represented by studies in which subjects left no trace of their personal participation, merely contributing isolated bits of behavior to a data pool, and a few in which subjects provided exhaustive data on a battery of tests and biographical inventories. However, the typical study represented an individual in terms of his sex (sometimes), treatment condition, performance scores, and ratings of partner or experimenter in posttest inquiry. Although the literature as a whole has elicited a wide range of potentially important information about persons, no single investigation either noted or utilized much information about any individual subject. 'Thus the task performances of subjects in current research remain uninterpretable as personality rlata in the absence of anchoring information.

An interesting sidelight is the new role of introspection in contemporary research. Apart from a fow stuclies in which the subjects' account of private experience constituted primary data, introspective reports are currently used $(a)$ in deriving pretest scores as a basis for assignment to experimental groups or $(b)$ "as a check on the effectiveness of the experimental manipulation."

The lime span of contemporary inquiry is short. 'The vast majority of published work was based upon a single session; less than one-fifth of reported studies involved more than a 2-week period, and rarer still were the few studies involving follow-up over significant periods of time. The only examples of investigators' extended delay of gratification were two follow-up studies (over 15 and 18 months) of smoking behavior (Johnson, 1968; Mann \& Janis, 1968) and a 3-year follow-up of mental retardates (Zigler, Balla, \& Buticrfield, 1968).

\section{What Is the Interpersonat Conlext of Research?}

With a few notable exceptions, the current mode of inquiry involves highly impersonal subject-experimenter relationships, "conscripted" subjects who are expected (and expect) to conform to research requirements with little explanation and little interpretive icedback.

Deception remains a salient feature of $\mathrm{cx}$ perimental inquiry. Over half of the total sample and $73 \%$ of the experimental studies relied upon deception as a means of manipulating major variables. There are, as Stricker (1967) has pointed out, many ways of deceiving subjects; most of these-cover stories, miscommunication of purpose, confederates, false interpretations of test performances, among others--were represented in the year's research. Moreover, deception often occurred in the context of imposing rather elaborate and clemeaning demands upon subjects. It is instructive to consider the subject's experience in a dissonance study (Kiesler, Pallak, \& Kanouse, 1968) which illustrates the potentialities of this research tradition:

A student who $(a)$ volunteered to participate in a study of "regional speech differences" for $\$ 1.50,(b)$ tape-recorded a prepared speech, and was (c) told that his recordings would be used in a nationwide survey and in classes at the university, $(d)$ sent to another building to be interviewed by a fake "assistant to the dean," (e) detained by a fake schedule delay, $(f)$ induced to participate in another survey while wailing, $(g)$ induced to reaffirm his "choice" to participate, $(h)$ told that he should report to another building a half-mile away, (i) rescued by another stooge who provided an cmpty classroom, (j) asked to write an essay contrary to his own beliefs, $(k)$ told that his essay would be published in the campus newspaper, $(l)$ required to read a prepared list of arguments, $(m)$ required to reaffirm his free choice to participate; he then $(n)$ wrote an essay, and was (o) required to "go down four flights of stairs, traverse approximately a block to a(nother) building . . and go up three flights of stairs . . ." (p) intervicwed by a fake "assistant to the dean" who expressed interest in the student's opinions, (q) asked to fill out an attitude questionnaire, $(r)$ required to provide ratings of his experience of the first task and of the first experimenter, $(s)$ required to provide ratings of his experience of choice, liking for the second task, and for the second experimenter, (t) asked about his parents' sociocconomic status, and (u) "was then completely debricfed, including an explanation of the study and hypothesis involved . . [Kiesler et al., 1968, p. 334].3

Debriefing was explicitly reported in only one-third of the rleception studies. Moreover, debriefing took a number of quite different

8 Incredibly, a professional symposium on "commitment" prior to the appcarance of this sturly praised this investigation for the ingenuity of its experimental design. 
forms. While a few studies reported thorough, integrative interpretations of experimental manipulations, more characteristic were several other types of debriefing: (a) Undoing (e.g., "After the subject completed the questionnaire, Dr. ... entered the office and debriefed him. Because all of the subjects had receiver a rather negative evaluation, they were delighted to learn that the evaluation was preprogrammed rather than an accurate reflection of their creative ability"-Aronson \& Cope, 1968, p. 10); (b) Rationalization (e.g., "After completing the questionnaire, the subject was queried as to possible suspicion and the purposes of the experiment and the need for deception explained"-Helmreich \& Collins, 1968, p. 78); and (c) Silencing (e.g., "Before leaving, the experimenter revealed the nature of the study and got the subject to promise not to discuss it with anyone"-Mills \& Jellison, 1968, p. 61).

While in many studies the nature of the tasks may be presumed to be obvious, and perhaps meaningful to the subjects, it is surprising that subjects' experience of research participation was not considered worthy of mention. Only 1 of the 226 studies (Steiner, 1968) noted provision for giving subjects a report of the findings of the investigation. When one considers that the vast bulk of the year's published research was made possible by the requirement of research participation as a "learning experience" in psychology courses, this lack of concern for subjects' cognitive clarity is remarkable.

One further aspect of the subject-experimenter relationship proved impossible to tabulate. Only in a small proportion of cases was it possible to determine whether the investigator or anonymous assistants had "run" the subjects or whether, in fact, the experimenter had ever seen his subjects.

\section{Questions We Can Neither Ask Nor Answer}

It is instructive to consider the range of personological questions which cannot be investigated by our current research methods. While the year's research literature provides a few isolated exceptions to many of the following generalizations, the central tendency of our current modes of inquiry is so strong as to mark a real barrier to knowledge.
We cannot study the organization of personality because we know at most only one or two "facts" about any subject. We cannot study the stability of personality, nor its development over epochs of life, because we see our subjects for an hour. We cannot study the problems or capacities of the mature individual, because we study late adolescents. We cannot study psychosexuality, because we avoid looking at distinctive qualities of masculinity and femininity as a focal problem. We cannot study how persons strive for their important goals, because we elect to induce motivational sets. We cannot study constitutional, temperamental variables because (apart from a few glances at increments in galvanic skin response under stress) we do not consider biological bases of personality. We cannot study the development and power of friendship-nor the course of true lovebecause we choose to manipulate interpersonal attraction.

Such a list of cognitive deficits in the collective psyche of the field might be extended at great length. Personality psychology would seem to be paying an exorbitant price in potential knowledge for the security afforded by preserving norms of convenience and methodological orthodoxy. Must these important, unanswered questions be left to literature and psychiatry? If so, what would be the use of our work?

Obviously, no single scientist, no single study, no single research tradition can possibly deal "scientifically" with anything so complex as a whole person. But the attempt can be made collectively and cumulatively. The present impoverishment of personality research is distressing because it suggests that the goal of studying whole persons has been abandoned. However, the fragmented and limited quality of current research may stem less from myopia or opportunism than from the absence of a conceptual framework for guiding inquiry in personality.

\section{A Typology of Research Approaches}

Kluckhohn and Murray (1949) remind us that every man is ". . like all other men, like some other men, and like no other men [p. 35]," and in an insightful truism have also offered an implicit model for order- 
ing the scope and methods of inquiry in personality. The typology of rescarch approaches suggested by this model corresponds to the major traditions from which personality study has grown: $(a)$ the experimental methods of laboratory psychology, (b) the correlational methods of differential psychology, and (c) the clinical methods stemming from the tralltion of French psychiatry and Viennese psychoanalysis. However, the typology has considerably more than mere historical interest, and may serve to illumine the present state of personality research and point toward a conceptually based set of solutions to present. problems.

". . . like ALL other men." The psycholo. gist working from this perspective seeks universals, the discovery of general laws of human nature. The emphasis is upon usychological processes; persons are essentially "carriers" of the variables under investigation. Research methods reflect the basic assumptions of this approach: persons are interchangeable; random assignment to treatment conditions is employed to insure control of icliosyncratic qualities which are "noise" in the generalist's inquiry. The basic assumption of the equivalence of subjects leads to further methodological implications: $(a)$ experimental manipulation of independent variables as the source of subject variability, (b) dimensional treatment of psychological variables, $(c)$ rclative deemphasis upon genetic variation and constitutional bases of individuality, and $(d)$ emphasis upon situational factors as major sources of variation in human nature. Among the many current examples of generalist tradition in personality research, one notes the extensive work on cognitive dissonance, the attempts to establish laws of interpersonal attraction and impression formation, the conditions under which cooperation and competition are elicited in interpersonal events.

". . like SOML other men." 'Ihis tradition studies psychological processes and their orgatization in different kinds of subjects; its aim is that of identifying group differences that make a difference. Such incuiry estahlishes typologies, charts the influence of moderator variables, and, substituting measurement for manipulation, tends to employ correlational methods (broadly conceived, in all their contemporary variations). Further, the differential approach tends to $(a)$ seck natural occurrences of the phenomena under investigation, (b) emphasize discontinuitieswhether of developmental level, character types, or social class-as correctives to an assumption of continuity, $(c)$ emphasize both genetic variation and cultural determinism as sources of critical differences, and $(d)$ emphasizo intrinsic intrapersonal structures as base lines for further inquiry. Current examples of the differential approach in personality rescarch include inquiry on the differences between internal and external controllers, different consequences of repression and sensitization as defense styles, the nature of sex differences in personality, and studies pointing to the limits of generalists' formulations--for instance, Bishop's (1967) demonstration that predictions from cognitive dissonance theory fail to fit the "anal" personality.

". . like NO other men." The clinical tradition, in its concern for mapping the intricate organization of psychological processes within the unique individual is the prototype; however, the individual approach includes less comprehensive kinds of inquiry, including "ipsative" methods (Broverman, 1962), "morphogenic" methods (Allport, 1968), a concern for "personal constructs" (Kelly, 1955 ) and inquiry focused upon the "representative case" (Schontz, 1965). While the potency of the case method in the development of personality study should be so obvious as to require no special emphasis, the particular quality of the contemporary (American) zeitgeist imposes a special prob$1 \mathrm{~cm}$ : the "clinical" tradition has come to connote a "helping" orientation totally extraneous to the method itself. (The relevance of case materials for strictly scientific inquiry is vividly demonstrated by the fact that geologists can derive from a few pounds of nonrandom moon-dust inferences about the structure and history of plancts.)

Inquiry in the individual tradition secks to (a) examine organization of psychological processes within the individual, (b) establish assessment methods deriving from the intrinsic structure and dynamics of the individual-and capable of representing this intrinsic structure, $(c)$ identify general psy- 
chological problems emerging from the examination of individual personality, and $(d)$ provide a field for testing the formulations derived from general and differential inquiry. Contemporary examples of the individual approach inclucle White's (1966) intensive studies of three "normal" personalities over a significant period of the life span, or, in a different mode, Alfert's (1967) demonstration that ipsative analyses of data on stress reactions revealed order and coherence which had eluded the generalist's "normative" approach to the same data.

Some of the conceptual and methodological issues involved in a comparable tripartite schema are presented in Emmerich's (1968) discussion of "classical," "differential," and "ipsative" models of development. However, while Emmerich's three models are presented as competing candidates, the three approaches presented here are conceived of as complementary rather than competitive alternatives. Tentative knowledge gained from any one approach must ultimately be weighed by alternative methods. A "general law" which operates only in certain kinds of people, or which can predict little of significance in an individual's life may prove very trivial in understanding personality. Similarly, an elaborate case study which neither inspires nor tests inquiry of a more general nature is basically irrelevant to personology.

This schema offers another way of assessing the current status of personality research: How well does current inquiry represent the person in these three fundamental aspects?

The 226 articles reviewed above were reexamined in terms of the present typology, and each article assigned to one of three categories as follows:

1. General. The research method disregarded preexisting subject variables and used random assignment to treatment conditions and/or treated subjects' scores as a continuous dimension.

2. Differential. The research method made at least minimal provision for identifying group differences on the basis of preexisting subject variables. Assignment to this category was "lenient" in the sense that a problem conceived in general terms was classified as "differential" if tests for qualitative differ- ences (e.g., sex differences) were reported.

3. Individual. The research method included extensive study of one or more individuals, and $(a)$ retained individual cases as the unit of analysis or $(b)$ included extensive case examples in presentation of findings.

The results of this analysis give a clear and consistent picture of the "generalist" bias in contemporary personality research, with 128 $(57 \%)$ of the studies disregarding subject variables. Ninety-eight ( $43 \%)$ of the studies classified as "differential" examined a somewhat limited set of bases of group differences (e.g., high versus low anxiety, repressors versus sensitizers, firstborns versus laterborns, males versus females); extreme groups defined on single dimensions rather than "lypes" were the norm. Finally, the analysis revealed that not a single published study attempted even minimal inquiry into the organization of personality variables within the individual.

Thus the present analysis provides a further basis for concern about the status of personality research. Conceivably, personological studies may appear from time to time in clinical and psychiatric journals not encompassed in the present review. But even if this could be demonstrated, what are the implications? Is personology to be left to the exclusive concern of the healer rather than the scientist? Should personality research be redefined as "the experimental study of personality fragments in artificial situations?" It is not so much the pretensions of the field as the neglect of legitimate and necessary pretensions which poses problems for the serious personologist.

Possible reasons for the current state of affairs, along with suggestions for enlarging the scope and relevance of personality study are considered in a later section. First, however, parallels between the methodological problems noted in personality literature and the issues raised in recent criticism of general psychological literature should be noted.

\section{Error, Ethics, and Disctplinary TNTEGRITY}

The pervasive effects of atmosphere, expectancies, and demand characteristics, long recognized by some psychologists (Allport, 1968; 
Kolly, 1955; Lewin, 1935), and recently rediscovered and developed as a research area by a newer gencration, now threaten to require a wholesale reexamination of much of psychology's substance. Recently, implications of this state of affairs have been examined in incisive comments of Arlelson (1969), Argyris (1968), and Schultz (1969), among others.

Adelson (1969), in a brilliant criticque of a year's worth of personality research, noted the rigidity and irrelevance of current methodology and the availability of more appropriate models of inquiry, but offered little o)timism about reform. Argyris (1968) pointed to "unintended consequences of rigorous research," noting that organization theory predicts current problems: the dependency or covert hostility of subjects caught in an authoritarian relationship, the "unionization" of subjects, the unintentional programming of people to become interpersonally incompetent. Schultz (1969) provided historical perspective on the role of the subject in psychological inquiry and underscored problems noted by recent critics of research methods: distortion of data through the use of irrelevant and nonrepresentative samples, deception of the deceiver, and the ethical problems involved in investigators' systematic disregard for the dignity and welfare of subjects.

The personologist-for whom all of these issues are of the deepest concern-finds that additional problems are posed by current research conventions. Among the unintended consequences of acquiescence in these conventions is the abandonment of the field of normal personality as a primary scientific enterprise. Surely this is a territory worth defending against benign encroachments of the experimental and social psychologists whose "process" orientation is more consonant with their mission, or the "abnormal" clinical psychologists whose concern with helping persons makes their journals and textbooks more receptive to person-centered inquiry.

Another serious consequence of acquiescence in current methodology is found in the abandonment of students and of curricular responsibilities (Carlson ${ }^{4}$ ). By permitting

${ }^{4}$ Carlson, R. (Chm.). Personality in the undergraduate curriculum. Symposium presented at the personality courses to become "adjustment" courses for nonmajors and "theory" courses for psychology majors, we are implicitly communicating a disbelief in the value or possibility of inquiry in personology. Thus psychologists are unintentionally cutting off sources of future scholars prepared to confront the intellectual problems of "personality" in a world where "depersonalization" has, for some years, been both a battle cry and a genuine human concern.

Further, a personologist, relatively sensitive to personality consequences of situational pressures and role demands, must be particularly concerned about the other edge of the clouble blade of current methodology. For that violation of human dignity experienced by subjects in manipulative-deceptive relationships equally demeans the psychologist who adapts to a norm of distrust, ${ }^{5}$ and comes to confuse games with the pursuit of science.

\section{Toward Solutions}

Once the depth and pervasiveness of the problem is genuinely confronted, solutions would seem to be well within the power of those seriously committed to the integrity and survival of the discipline. Several relevant proposals have been advanced by recent critics of the general psychological scene.

Argyris' (1968) proposals include the important conceptions that subjects should be given greater control and influence, longer time perspective, and greater internal involvement in research projects. Noting that contamination of research by subjects' expectancies is inevitable, he pointed out that greater control of such contamination can be achieved by research methods which increase awareness of such expectations. Moreover, his empirical work demonstrating the resistance

meeting of the Amcrican Psychological Association, San Francisco, August 1968.

5 An incident illustrating the depth and duration of this problem occurred in the writer's experience of interviewing a prospective jumior colleague several years ago. Askerl about his own experience as a student in a West Coast university, the candidate recalled his experience of hearing about the assassination of the late President Kennedy in a psychology class, his calm assumption that this was naturally an expcrimental manipulation, and his continued disbelief in the reality of the tragedy for some time--on "professional" rather than human grounds. 
to change of "behavior that is internalized, highly potent, and related to ... feelings of intellectual and interpersonal competence ...." strongly supports Argyris' interpretation that "the more researchers study such behavior, the Jess they may need to worry about such contamination [p. 195]."

Schultz (1969) posed two basic dimensions of reform: $(a)$ the broadening of inquiry to include more representative noncollege samples, and (b) development of research methods which would reflect ethical responsibility and a contemporary image of man and of the scientific enterprise.

Toward achievement of broad-gauged sampling, Schultz gave an ambivalent endorsement to Rosenthal's (1966) suggestion that independent data-collection centers undertake execution of studies designed by academic investigators, in the belief that standardization of experimenter bias and the procurement of more representative samples would correct some of the serious deficiencies of current research. While the problem of the expense of establishing and maintaining such centers is noted by Schultz, more serious problems are also involved. From the standpoint of the present critique, this proposal would seem to exacerbate fundamental problems. By increasing the distance between the investigator and his data, and by decreasing his personal involvement and responsibility, the Rosenthal proposal would extend the investigator's license to ignore the relevance of his inquiry and to exploit or ignore dependency and counter-manipulation of subjects. Conceivably, the Rosenthal proposal could have some merit in broadening inquiry on certain impersonal problems of classical experimental psychology. But the overall effects of establishing such an elaborate hand-washing apparatus would seem to be lethal for those engaged in issues of personality and interpersonal relationships.

Toward solution of the second class of problems--ethics and relevance-Schultz gave tentative endorsement to Kelman's (1967) proposal of role playing as a research technique and to Jourard's (1968) suggestion that mutual self-disclosure by experimenter and subject might dispel the cloud of distrust which surrounds much current inquiry.
Undoubtedly, Kclman's (1967) suggestion for cooperative engagement of the subject's imaginative resources in role playing the confrontation of psychological problems is a notable improvement over current deceptivemanipulative methods. However, this proposal does not touch critical issues of problem finding or of real-life involvenent; and one can imagine that the role-playing technique might even perpetuate (by legitimizing) the systematic irrelevance of much psychological research. As Schultz (1969) noted, the value of this method would be highly dependent upon characteristics of subjects and of subject-experimenter relationships. Fundamental personological questions (e.g., What kinds of people can invest themselves in what kinds of role playing?) entirely bypassed in this proposal would define the limits of its relevance. There is a clear (but probably small) place for the role-playing technique in investigating a wide range of theoretically significant problems; considerable thought should be given to these limits before the technique is blessed as a solution to our current malaise.

Jourard's (1968) recommendation of mutual self-disclosure poses somewhat different problems. As Schultz (1969) noted, the personality of the investigator would be a major factor-along with issues of the time and expense involved. But more serious objections should be noted. Admittedly, almost any methods of restoring confidence, trust, and dignity in subject-experimenter relationships could be justified at this point in time. However, the correction of a destructive relationship can, at most, create an atmosphere in which genuine research is possible; it does not constitute a research method. Moreover, there are real risks that experimenter and subject alike may be seduced by the "togetherness" aspects of interaction; that the Jourard proposal, in the hands of investigators characterologically unsuited to this mode of inquiry, might cloud the purposes of scientific inquiry as thoroughly as the manipulativeexperimental techniques in current vogue. There are a number of ways of deriving irrelevant gratifications from research, and in the absence of scientific commitment and conceptual clarity, soft hearts are probably no better than hard heads as tools of the trade. 
The climate of change, of self-examination, of genuine concern for reform of psychological inquiry is unmistakable. In this context, the present critique of several current proposals stems from a concern that basic issues may be obscured by the sense of urgency toward reform. At the risk of oversimplifying several thoughtful contributions, current reform proposals appear to address two quite different issues of control and of alienation. Control of unwanted variance (whether generated by inappropriate sampling, experimenter bias, or subject expectancy) and counteracting forces toward alienation (of experimenter from subject, of experimental inquiry from real-life relevance) are the explicit goals of most current proposals, or the rationales for more fundamental ones (c.g., Argyris, 1968). However, most of the proposals fail to deal explicitly with issues of relevance of method to problem, or to locate clearly the responsibility for various reforms. Some explicit consideration of these issues seems warranted.

On the relevance of subject samples. Most of the current concern about overreliance upon undergraduate students as research subjects (ci. Schultz, 1969) reflects the generalist's concern with nonrepresentative samples which constrain the generality of laws to be cstablished from inquiry. There exists sufficient evidence of "bias" in college samples (volunteer bias, birth-order effects, sociocconomic sclectivity) to establish that undergraduate students are probably not representative of humankind.

But a more serious concorn may be raised about the misuse, rather than the use of college students as research subjects. For students, as a group, possess many characteristics which make them highly appropriate subjects for personality rescarch: they are curious, intelligent, motivated to explore their lives and experiences, capable of articulate introspection-and their life situations generally provicle both time and meaningful settings for research participation. Yet it is precisely this set of subject characteristics which lends to be ignored (or violated) in current rescarch conventions. When the student's intrinsic motivation is "controlled" by external requirements of research participation and by induction of motivational sets, when his introspective capacities are constrained by the formats of rating scales and checklists, when his curiosity is violated by deception and false or partial fcedback, the very characteristics which recommend him as a research subject are thrown away.

Moreover, certain limitations upon the generality of student-based research are equally ignored. Clearly, students are "unfinished" personalities. Coherent changes in ego structure within and beyond college years have been demonstrated in a wide variety of studies ranging from Constantinople's (1969) charting of ego changes in questionnaire responses over the undergraduate years through White's (1966) intensive longitudinal clinical studies of students whose postcollege years revealed surprising but theoretically significant consolidations and restructurings of intrapersonal and interpersonal dynamics.

While the year's published personality research occasionally noted the selection of samples considered intrinsically relevant to the research problem (e.g., a series of obesity and eating studies published in the October 1968 Journal of Personality and Social Psychology), the typical study evidently used college students simply because they were there.

"Reform" proposals directed toward broadening of research samples need to be based upon thoughtful consideration of the subject characteristics of intrinsic relevance to research problems. Once such criteria are established, a range of populations might be sampled: colleagues, community adults, friends and families of students-along with a range of special populations (e.g., military personnel, prisoners, etc.) whose experience of special situations might illumine important problems rarely cncountered by subjects from the general population. Moreover, a vast range of individuals whose biographies and personal documents are capable of transcending demographic constraints of usual research samples is available for inquiry in general, differential, and individual terms, for instance, Cox's (1926) or Goertzel and Goertzel's (1962) studies of gifted individuals; Baldwin's (1942) analysis of personal letters.

On the relevance of research strategies. Three considerations may summarize the status of the field: $(a)$ over three-fourths 
of the personality literature surveyed used "experimental" methods; (b) these experimental designs relied upon "remote control" of variables which, as Schontz (1965) has noted, are especially vulnerable to ambiguity and error; $(c)$ within general psychology, there is an increasing conviction that strictly "experimental" methods are incapable of dealing with central aspects of human psychology (Deese, 1969; Walker, 1969).

One clear recommendation for personality study emerges from a serious reading of general psychological research criticism: until "experimental" methods are developed which can $(a)$ accommodate present knowledge and (b) offer relevant new knowledge not attainable through development of other scientific tools, "experimental" studies of personality should be clearly deemphasized. This is not so radical a proposal as might appear, for it simply asks "time out" for untangling a basic confusion in the field. One can study persons in experimental situations-but one cannot "study personality experimentally." As Sarason (1969), among others, has observed: "An experimental approach is useful in analyzing reactions of particular people in special situations [p.v; italics added]." Only as experimental inquiry derives from concern for preexisting subject variables, and provides experimental treatments theoretically focused upon such subject characteristics can experimental methods hope to illumine personality structure or dynamics.

Meanwhile, the most serious thought should be given to alternative strategies of inquiry. Tyler (1959), in a paper which should be recxamined by all personality researchers, has presented a compelling case for the abandonment of dimensional approaches to individuality on the pragmatic grounds that this traditional approach has failed to improve upon predictabilities. As an alternative, Tyler recommended construction of personality inquiry in terms of "choice" and "organization"along with a search for measurement approaches capable of representing individuality. Problems and possibilities for developing approaches to reliability and validity in research on choice were presented in a further paper (Tyler, 1961), which incidentally serves as a model of an investigator's serious involvement in the intrinsic problems of research.

A wide variety of alternative research strategies has become available in recent years: a range of "nonreactive" measures (Webb, Campbell, Schwartz, \& Sechrest, 1966), methods of naturalistic observation (Barker, 1963; Raush, 1967), methods for investigating the single case (Davidson \& Costello, 1969) to name a few. Meanwhile, psychologists would do well to become acquainted with the work of contemporary anthropologists who have developed concepts and methods of great relevance to personality study. ${ }^{\circ}$

On the scope of personality study. Over 30 years ago, Murray (1938) noted that "the reason why the results of so many researches in personality have been misleading or trivial is that experimenters have failed to obtain enough pertinent information about their subjects. Lacking these facts, accurate generalizations are impossible [p. ix]." This comment could stand as a summary of current workwith the important amendment that the accumulation of more "facts" (including much unassimilated data collected through Explorations in Personality) has not provided, nor is likely to provide, the basic generalizations needed in this field.

Beyond noting the extraordinarily narrow and impoverished scope of current personality research, what suggestions for broadening and deepening inquiry might be advanced? At a very general level, this problem involves setting the collective level of aspiration of the entire field to include a shared responsibility that personality be investigated in its basic aspects ("like all other men, like some other men, like no other men"). Within the context of any single investigation, this problem requires that the individual researcher pay the most serious attention to the need for obtaining information which is $(a)$ potentially available, and $(b)$ necessary to full

\footnotetext{
a Interestingly, the insularity of the psychologist secins to be increasing in recent years. While anthropologists have consistently "borrowed" psychological concepts and methods, psychologists" awareness of anthropological inquiry often seems to have been arrested at the level of Malinowski and early Mearl, and our "borrowing" largely limited to fickls of mathematics and physics.
} 
understanding of the intrinsic problem-whether or not such information is explicitly dcmanded by his immediate research design, ${ }^{7}$ Glaring examples of current failure to consider appropriate breadth of scope may be drawn from experimental research in which (a) subjects' phenomenological reports are routinely sought (via checklists, ratings, and other means) and equally routinely nonanalyzed and nonreported; and $(b)$ even more serious misuse of subjects' reported experience to exclude individuals who do not readily accommodate to the Procrustean theoretical bed via "dropping" or "reassigning" recalcitrant subjects (as in dissonance research-cf. Chapanis \& Chapanis, 1964) or via deliberate nonsampling of subjects known to fail to conform to theoretical expectations (e.g., Katz, 1967).

More positively, the investigator should continually reconsider that the point of inquiry is to understand the phenomena under investigation. Inevitably, this requires attention to the intrapersonal context of research performances-here research subjects' willingness to provide this context could be developed much more fully and fruitfully than we are inclined to do (cf. Lewin, 1935).

More specific recommendations for extending the scope of inquiry in sclected aspects may also be noted:

1. Critically important problems concerning the personality development and change clearly require longitudinal study. Why are Iongitudinal studies so rare? The traditional rcasons are of two sorts: (a) longitudinal studies require such massive commitments of time and research technology as to demand large-scale organization support; and (b) obsolescence of research concepts and methods over the life span of a longitudinal study pose problems.

However, a second look at the underlying assumptions is in order. If "longitudinal study" is identified with such large-scale endeavors as the Fels studies (cf. Kagan \&

\footnotetext{
7 A colleague has offered an instructive example from his own work: in a sludly (Levy, 1969) which involved asking 2800 school children about their preferences for Card IV versus Card VII of the Rorschach, he failed to inquire, Why? (N. Levy, personal communication, September 1969.)
}

Moss, 1962) or the Berkeley Growth Study (Jones \& Bayley, 1941) the first of these traditional deterrents is obviously relevant; but the Fels and Berkeley studies offer demonstrations that longitudinal data collected by imaginative and responsible investigators are remarkably fruitful fields for "up-dated" analyses which keep pace with advances in the field. However, more modest studies are urgently needed in the personality field and are quite feasible. Short-term (e.g., 5-year) investigations of selected aspects of personality would immensely enrich inquiry, and need not involve massive and comprehensive sampling and instrumentation, as seen in such examples as Escalona and Heider's (1959) predictions of nursery school behavior from observations in infancy, E. L. Kelly's (1955) 20-year study of marriage partners, or Carlson's (1965) 6-year follow-up study of sex differences in the basis of self-esteem. (Incidentally, the last example illustrates the feasibility of longitudinal investigation conducted without any financial or formal institutional support whatsoever.) Provision for longitudinal follow-up studies could be readily built into a wide range of personality studies with very little additional effort- and with extraordinarily rich potentialities for advancement of knowledge.

2. Somewhat paradoxically, personality research might be strengthened and enriched by becoming an incidental by-product (rather than the focus) of naturally occurring datacollection situations. This rather obscure point may, perhaps, be illustrated with the writer's personal experiences in teaching upper division personality courses: In developing primary instructional purposes, I have often asked students to produce brief, introspective (and anonymous) accounts of selected personality constructs for use in class projects exploring methods of personality assessment. Such materials have often yielded "incidental" data of considerable relcvance and richness for later testing of theoretical formulations which were not envisaged at the time of original data collection (cf. Carlson, 1971).

The relevance of such "incidental" data collection to psychology courses-where the vast bulk of personality research is conducted-is obvious (and might also serve important 
additional purposes of increasing the relevance of psychology instruction to stuclents' purposes of exploring their own lives, and of incidental "recruitment" of potential scholars through the experience of disciplined inquiry or personological questions). However, in principle, this suggestion would apply equally to many other data-gathering settings, and fundamentally involves the use of informal "archival records" (whether freshman English themes, college-application essays, contents of employees' suggestion boxes, comments of subjects in instructional-methods-evaluation studies, etc.) as unobtrusive measures of personality functioning in natural situations.

3. Finally, as a general consideration relevant to many kinds of research problems, it is safe to assume that most subjects are willing to tell us much more than our current research designs ask about their experiences and the personal meanings of these experiences. Psychology is probably much poorer for its disinclination to listen to such potentially important messages; hopefully, the recent demise of naive behaviorism will liberate us to take seriously human construction of experience as more than merely countable "responses" or "verbal reports."

On the relevance of social-psychological context. Two models of subject-investigator relationships may be discerned in current psychological inquiry: (a) a contractual relationship in which the subject is an "employee," and $(b)$ a collaborative relationship in which the subject is a "colleague." Because the contractual model appears to be the increasingly dominant one (and even "reform" proposals urging the collaborative mode contain strongly contractual features), some of its implications need to be examined.

The contractual relationship seems to have developed in the service of scientific concerns and to reflect some basic values and assumptions about human nature. Thus, paying subjects for their services--whether in terms of money or course credit, or both-is seen as minimizing volunteer bias, minimizing the dependency of subjects, offering a more meaningful model for the participation of noncollege samples, avoiding troublesome problems of overdetermined motives for research participation-and as expressing concerns for equity, for fairness and regularity in defining rights and roles of subjects. Undoubtedly a contractual model is capable of correcting certain abuses of research relationships and offers a relevant model for some kinds of inquiry. However, important consequences of the use of this model should be examined. The "contract" encourages investigators' denial of the intrinsically "volunteer" quality of participation in personality research. Moreover, by maintaining orderliness of one set of contractual obligations, investigators are enabled to deny the legitimacy of other fundamental obligations which are not written into the contract. (Two examples may illustrate this point: (a) scrupulous observation of obligations as an "experimenter" enables the academic researcher to ignore his equally relevant obligations as a "teacher" to provide maximum cognitive clarity to student-subjects; (b) the concept of "debriefing"--a military metaphor of extremely dubious relevance to psychological inquiry-implies that it is possible to undo an experimental set, and encourages the investigator to ignore his responsibility for consequences to the subject which were not intended.) liurther, a host of troubles have been introduced into the research enterprise as subjects, increasingly cynical about psychological inquiry and frankly motivated to pick up extra money, have tended to give only perfunctory attention to research tasks.

Fundamentally, the contractual model imposes its own character upon research; it can only be appropriate in the investigation of contractual relationships, and even there may lead to immense confounding of the rescarch findings by the effects of research context. In the study of personality, there are very few problems or occasions for which a contractual model is capable of providing valid information about persons' spontaneous ways of organizing experience. As Loevinger (1966) has pointed out, a "contractual" interpersonal style is characteristic of particular stages of ego development, and thus important differences among individuals are necessarily obscured when this interpersonal mode is also built into the context of inquiry.

The alternative a collaborative modelhas its own problems and its own defining 
characteristics. Basically, the collaborative model does not insist upon control or standardization of motivation for research participation, but assumes that $(a)$ subjects and settings are chosen for their intrinsic relcvance to the problem at hand; and $(b)$ the basic motive for research participation must be the subject's intrinsic involvement in exploring his own experience. (This motivation may take many equally appropriate forms: that of the patient wishing to be helped, the student wishing to understand and master his life experience, the excluded or alienated person who wants to assert and explore his individuality, the "intelligent layman" who wants to express and understand his values and concerns in an intellectual framework.) The collaborative model does not rest upon narrow or egalitarian assumptions of undifferentiated "togetherness," but assumes that subject and investigator have their different kinds of expertise which are united by a common belief in the possibility and value of clarification of experience through research participation. Unquestionably, a collaborative model is more demanding and more rewarding to subject and experimenter alike. It demands more candor and more thought on the part of the investigator in posing research problems, in engaging appropriate subjects, and in interpreting the nature of the experience; it demands more involvement from the subject, and offers the important reward of having his experience taken seriously. From the standpoint of personality research, these conditions are likely to provide more genuine understanding of human personality organization and development. ${ }^{8}$

So much serious exploration of the ethical implications of research methorlology has appeared in recent literature that very little needs to be added on this score. Our loss of innocence now requires that the psychologist give very serious attention to his own part in the research enterprise, accepting the responsibility for his own choices and for the consequences of these choices. While several specific research recommendations might follow from the recent Fnglightenment, the most general one would be the commandment: Do not administer to any subject a rescarch treatment you have not first "taken" yourself.

${ }^{8}$ An cxample of such collaborative research is provided by Sanford (1969).
Although this proposal tends to elicit initial incredulity and irritation from professional colleagues, it is a completely serious recommendation: one which could enable psychologists to examine and discard tendencies to impose unnecessary and brutally exhaustive testing programs or elaborate and unnecessary manipulation of their subjects-and, more importantly, engage the thoughtful participation of the psychologist as a person toward enriching the relevance of his inquiry. Obviously, this recommendation would eliminate deception as a technique of inquiry. However, there is considerable reason (Kelman, 1967; Stricker, 1967; Stricker, Messick, \& Jackson, 1967) to believe that this would be a very minor loss as contrasted with the increased veridicality and responsibility of nondeceptive research.

Toward disciplinary responsibility. Clearly, the investigator must be permitted and encouraged to define and explore problems in terms of their intrinsic merit. However, a climate of scientific freedom is not equivalent to a norm of laissez-faire. Since scientific inquiry is currently conducted through an elaborate set of institutional apparatus, there are clear responsibilities at various levels of this network. Insofar as the individual investigator neglects social responsibility and ethical concerns, the agencies of public policy must fill that vacuum. Recent Public Health Service directives concerning the welfare of human subjects represent a benign exercise of this responsibility; more restrictive and irrelevant constraints upon psychological inquiry should be anticipated if psychologists fail to consider fully their own responsibilities in the conduct of research.

Among several ways in which the discipline might cooperate toward development of more responsible and meaningful inquiry, the following suggestions are offered:

1. Psychology departments have a major concern for the integrity of instructional purposes upon which requirements for research participation are based. Thus, explicit plans for valid interpretations of problems, methods, and findings $(a)$ to individual subjects, and (b) to class groups from which subjects are recruited-along with (c) "feedback" from student subjects-should be required of investigators who use departmental research- 
participation requirements as a means of obtaining subjects.

2. Psychological journals inevitably play a major part in determining the content and methods of scientific inquiry, and thus bear a major responsibility for the quality of research. (This responsibility is particularly clear in the case of journals of the American Psychological Association which are directly supported by and responsible to the entire discipline.) Among the obvious ways in which our journals might exercise this responsibility, three specific suggestions are noted: (a) Intrinsic relevance and responsibility of inquiry could be fostered by the adoption of Loevinger's (1968) two-fold suggestion that published studies should be based upon samples clearly relevant to the problem and upon replicated findings. (b) Explicit attention to well replicated findings as "control" variables should be required for publication. An obvious example is the suggestion of several investigators (Carlson \& Carlson, 1960; Garai \& Scheinfeld, 1968) that sex differences be considered in al! published studies employing mixed-sex samples. Developmental Psychology, presently unique in making this an explicit criterion, provides a model of editorial responsibility in this sphere. (c) Since journals, unlike individual investigators, have unique responsibility and power to consider the total import of inquiry in any field, considerations of balance and emphasis fall within the domain of journal editors. (An example from recent history is the Journal of Social Psychology's giving explicit priority to crosscultural research.) From the standpoint of the present critique, those journals primarily concerned with personality research should exercise their responsibility toward correcting imbalance in current research by giving priority to investigations of personality organization within individuals, and to inquiry on qualitative, typological bases of personality organization since the present survey of personality literature clearly shows these facets neglected in favor of general experimental studies.

\section{Where Is the Person in Personality Research?}

That the person is not really studied in current personality research is clearly shown in the survey of the literature. But is it possible that the product of this inquiry, in its basic denial of the importance of personality, may be a faithful projection of the real lives and the real world of personality researchers? This is a chilling thought-but one which deserves very serious examination.

Consider the passage with which Adelson (1969) ends the methodological section of his review of personality research:

We like to pretend that our choice of methods is dictated by scientific considerations alone. In fact, the exigencies of the academic marketplace play an important and perhaps decisive role. The methodological problems we have noted... reflect the pressure for quick publication. There is reason to doubt that there will be rapid reforms in methodology until there is some reforn of the university [p. 222, italics added].

It would be difficult to find a clearer statement of real clespair: Adelson is suggesting that personality rescarchers really are such willing or powerless captives of field forces of academic and professional status definitions that they must await liberation at the hands of some external force which will alter the environment.

Conceivably, studies of the "sociology of knowledge" might add to our awareness ofand liberation from - uncxamined constraints upon inquiry. However, such studies are unlikcly to tell us much more than we already know: that scholars are attracted to research problems through the influence of potent research models and teachers; that their training, support, publication, and visibility are contingent upon the "cumulative" character of potential contributions; that innovative methods or findings are unlikely to achieve an impact until the field is prepared to assimilate them. From the standpoint of the present critique, it might be more valuable to develop inquiry in the "personology of knowledge," examining the personality characteristics which determine an investigator's resonance to and involvement in various substantive problems, his openness to innovations in content and method, his independence of external supports in pursulit of inquiry, and his capacity to transmit a sense of personal involvement in disciplined inquiry to his colleagues and students.

Pending such inquiry, it may be that the current trends may continue. However, even within these constraints, a more optimistic 
prognosis could be supported by a range of literature suggesting that significant personal change can result from the confrontation of the discrepancy between one's behavior and one's values; that such changes involve the engagement of one's basic "ideoaffective postures" (Tomkins, 1965); and that such changes may be facilitated in times of widespread questioning and change. That we live in such a time of social change scarcely needs documentation; the present critique is offered as part of the discipline's clear confrontation of its value-behavior discrepancies, and urges the engagement of our basic cognitive and affective commitments toward more relevant and responsible inquiry.

The original question-Where is the person in personality research?--may have two different answers. If the fully functioning person is not portrayed in our current personality literature, we may simply be looking in the wrong place. There are serious investigators of personality-perhaps increasingly found outside psychology - whose inquiry and understanding will continue to appear in the books and papers which illumine the field. But this is no radical departure from the past. If White, Erikson, Tomkins, or Keniston-to mention a few prominent personologists-are not indexed in the volumes of our current personality journals, neither were Freud, Jung, Angyal, or Piaget. We might might simply retitle our journals to reflect their functions somewhat more accurately, and proceed as before.

A second answer is this: The person is there--in our personality laboratories, classrooms, and in the community-waiting to be engaged in serious studies of personality once those of us who investigate personality become able to invest ourselves in this task.

\section{REFLRENCES}

Adruson, J. Personality. In P. H. Mussen \& M. R. Rosenzweig (Jids.), Annual review of psychology. Palo Alto, Calif.: Annual Reviews, 1969.

AlFen, E. An idcographic analysis of personality differences between reactors to a vicariously experienced threat and reactors to a clirect threat. Journal of Rxperimental Research in Personality, 1967, 2, 200-207.

ALLPoRT, G. The person in psychology: Selected essays. Boston: Beacon, 1968.
Argyris, C. Some unintended consequences of rigorous research. Psychological Bulletin, 1968, 70, 185. 197.

Aronson, E., \& Core, V. My enemy's enemy is my friend. Journal of Personality and Social Psychology, 1968, 8, 8-12.

Bacdowin, A. L. Personal structure analysis: A statistical method for investigating the single personality. Journal of Abnormal and Social Psychology, 1942, 37, 163-183.

BArTser, R. G. (Ed.) The stream of behavior: Exploration of its structure and content. New York: Appleton-Century-Crofts, 1963.

Baughman, E. E., \& Welsir, G. S. Personality: A behavioral science. Englewood Cliffs, N. J: Prentice-Hall, 1962.

Bisfor, F. V. The anal character: $\Lambda$ rebel in the dissonance family. Journal of Personality and Social Psychology, 1967, 6, 23-36.

Broverman, D. M. Normative and ipsative measurement in psychology. Psychological Review, 1962, 69, 295-305.

Carrson, F. R., \& Carlson, R. Male and female subjects in personality research. Journal of $A b$. normal and Social Psychology, 1960, 61, 482-483.

Caksson, R. Stability and change in the adolescent's self-image. Child Development, 1965, 36, 659-606.

CArssor, R. Sex differences in ego functioning: Exploratory studies of agency and communion. Journal of Consulting and Clinical Psychology, 1971, in press.

Ciralants, N. P., \& Chapanis, A. Cognitive dissonance: Five years later. Psychological Bulletin, $1964,61,1-22$.

Constantinople, A. An Eriksonian measure oi personality development in college students. Developmenlal Psychology, 1969, 1, 357-372.

Cox, C. M. Genetic studies of genius. Stanford: Stanford University Press, 1926.

Davidson, P. O., \& Costello, C. G. $N-1$ : Experimental studies of single cases. Now York: Van Nostrand Reinhold, 1969.

Drese, J. Bchavior and fact. American Psychologisi, $1969,24,515-522$.

Emmericis, W. Personality development and concepts of structurc. Child Development, 1968, 39 , 671-690.

Eschlona, S., \& Heider, G. Prediction and outcome: A study in child development. New York: Basic Books, 1959.

Garai, J. E., \& Schrinterid, A. Sex differences in mental and behavioral traits. Genetic Psychology Monographs, 1968, 77, 169-299.

Gonrtzer, V., \& Gorestzer, M. G. Cradles of eminence. Boston: Little, Brown, 1962.

Hetmptich, R., \& Corlins, B. E. Studies in forced compliance: Commitment and magnitude of inducement to comply as determinants of opinion change. Journal of Personality and Social Psychol ogy, 1968, 10,75.81.

Jonnson, R. E. Smoking and the recluction of cognitive dissonance. Journal of Personality and Social Psychology, 1968, 9, 260-265. 
JONES, H. E., \& BAYLEY, N. The Berkeley growth study. Child Development, 1941, 12, 167-173.

Jourard, S. M. Disclosing man to himself. Princeton, N. J.: Van Nostrand, 1968.

KAGAN, J., \& Moss, H. Birth to maturity. New York: Wiley, 1962.

Karz, I. The socialization of academic motivation in minority group children. Nebraska Symposium on Motivation, 1967, 15, 133-191.

KELIX, E. L. Consistency of the adult personality. American Psychologist, 1955, 10, 659-681.

KELLY, G. A. The psychology of personal constructs. Now York: Norton, 1955.

Kelman, H. The problem of deception in social psychological experiments. Psychological Bulletin, 1967, $67,1-11$.

Kiesler, C. A., Palidak, M. S., \& Kanouse, D. E. Interactive effects of commitment and dissonance. Joumal of Personality and Social Psychology, 1968, 8, 331-338.

Kluckrolin, C., \& Murray, H. A. Personality in nature, society, and culture. (1st ed.) New York: Knopf, 1949.

LEVY, N. Affective preference for card IV or VII of the Rorschach as related to sex and age. Perceptual and Motor Skills, 1969, 28, 741-742.

LEwIN, K. Dynamic theory of personality. New York: McGraw-Hill, 1935.

Loevinger, J. The meaning and measurement of ego development. American Psychologist, 1966, 21, 195-206.

Lorvinger, J. The "information explosion." American Psychologist, 1968, 23, 455.

Maccony, E. (Ed.) The development of sex differences. Stanford: Stanford University Press, 1966.

Maddr, S. Personality theories: A comparative analysis. Homewood, Ill.: Dorsey, 1968.

Mann, L., \& Janis, I. L. A follow-up study on the long-term effects of emotional role playing. Journal of Personality and Social Psychology, 1968, 8, 339-342.

Merratian, A. An analysis of personality theories. Englewood Cliffs, N. J.: Prentice-Hall, 1968.

MnLs, J., \& Jellison, J. M. Avoidance of discrepant information prior to commitment. Journal of Personality and Social Psychology, 1968, 8, 59-62.

MTsches, W. Personality and assessment. New York: Wiley, 1968.

Murphy, G. Psychological views of personality and contributions to its study. In E. Norbeck, D. Price-Williams, \& W. McCord (Eds.), The study of personality. New York: Holt, Rinehart \& Winston, 1968.

MuRRAy, H, A. Explorations in personality. New York: Oxford, 1.938.

OrNe, M. T. On the social psychology of the psychology experiment: With particular reference to demand characteristics and their implications. American Prychologist, 1962, 17, 776-78.3.
O'Toole, R., \& Durne, R. Baby feeding and body sway: An experiment in George Herbert Mead's "Taking the role of the other." Journal of Personality and Social Psychology, 1968, 10, 59-65.

RaUSH, H. Naturalistic aspects of the clinical research method. Human Development, 1967, 10, 155-169.

RosenthaL, R. Experimenter effects in behavioral research. New York: Appleton-Century-Crofts, 1966.

S.ANFond, N. Will psychologists study human problems? American Psychologist, 1965, 20, 192-202.

SANroRd, N. Research with students as action and education. American Psychologist, 1969, 24, 544546.

SaRASON, I. Contemporary research in personality. Princeton, N. J.: Van Nostrand, 1969.

SCrtonTz, F. C. Research methods in personality. New York: Appleton-Century-Crofts, 1965.

Scrultz, D. P. The human subject in psychological research. Psychological Bulletin, 1969, 72, 214-228.

Sterner, I. D. Reactions to adverse and favorable evaluations of one's self. Journal of Personality, $1968,36,553-562$.

Strickirr, L. J. The true deceiver. Psychological Bulletin, 1967, 68, 13-20.

Stricker, L. J., Messick, S., \& JAckson, D. N. Evaluating deception in psychological research. (Research Bulletin 68-59) Princeton, N. J.: Educational Testing Service, 1968.

Tomkins, S. S. $\Lambda$ ffect and the psychology of knowledge. In S. S. Tomkins \& C. E. Izard (Eds.), Affect, cognition, and personality: Empirical studies. New York: Springer, 1965.

TYLFR, L. Toward a workable psychology of individuality. American Psychologist, 1959, 14, 75-81.

TYLER, L. E. Research explorations in the realm of choice. Journal of Counseling Psychology, 1961, 8, 195-201.

WaLker, E. L. Experimental psychology and social responsibility. American Psychologist, 1969, 24, 862-868.

Webi, E. W., Camprert, D. T., Schwartz, R. D., \& Secrrass, I. Unobtrusive measures: Nonreactive research in the social sciences. Chicago: Rand McNally, 1966.

Wuits, R. F. Lives in progress. (2nd ed.) New York: Holt, Rinehart \& Winston, 1966.

Wusson, W., \& Insko, C. Recency effects in facc-toface interaction. Journal of Personality and Social Psychology, 1968, 9, 21-23.

Zigler, E., Batia, D., \& Butterfield, E. C. A longituclinal investigation of the relationships between preinstitutional social deprivation and social motivation in institutionalized retardates. Journal of Personality and Social Psychology, 1968, 10, 437445 .

(Received September 30, 1969) 